Trabalhonecessário

Issn: $1808-799 X$

ano 14, número $24-2016$

\title{
IMPACTOS DA TERCEIRIZAÇÃO SOBRE AS RELAÇÕES DE TRABALHO; REFLEXÕES ACERCA DO PROJETO DE LEI $4330 / 2004^{1}$
}

\author{
Cleide Francisca de Souza Tano² \\ Alessandra Aparecida Franco ${ }^{3}$ \\ Robson Luiz de França ${ }^{4}$
}

\section{Resumo}

A discussão sobre a terceirização no Brasil surgiu a partir do processo de reestruturação das empresas e com a abertura econômica no fim da década de 1980. Este artigo visa discutir o fenômeno da terceirização no Brasil e seus impactos sobre as relações de trabalho, a partir da aprovação recente do Projeto de Lei 4330/2004. Buscou-se discutir os fatores que caracterizam as relações de trabalho, nos serviços terceirizados, assim como as questões relacionadas com as consequências dos processos de terceirização para os trabalhadores. Fundamentaram o trabalho pesquisas bibliográfica e documental centradas na legislação brasileira e manifestações das principais centrais sindicais do país, a Central Única dos Trabalhadores (CUT) e a Força Sindical, as quais conforme Galvão (2013), assumiram posições distintas em relação à política neoliberal e ainda em manifestação da Conlutas (CLS). A perspectiva epistemológica adotada é a Materialista Histórica. Espera-se que este trabalho possa instigar novos debates, reflexões e olhares acerca desta temática.

\footnotetext{
${ }^{1}$ Este artigo é parte integrante de trabalho apresentado e publicado em anais, do II Seminário Internacional Desafios do Trabalho e Educação no Século XXI, organizado pelo PPGED/UFU, em 2015.

2 Bacharel em Administração, mestranda em Educação, na Faculdade de Educação da Universidade Federal de Uberlândia.

3 Bacharel em Administração, doutoranda em Educação na Faculdade de Educação da Universidade Federal de Uberlândia. Professora na Faculdade Triângulo Mineiro, e também professora na Universidade do Estado de Minas Gerais - Campus Ituiutaba.

${ }^{4}$ Doutor e Mestre em Educação. Membro do Grupo de Pesquisa Trabalho, Sociedade e Educação. Professor Associado da Universidade Federal de Uberlândia - Faculdade de Educação Professor do Programa de Pós-Graduação em Educação.
} 


\title{
Trabalhonecessário
}

Issn: $1808-799 X$

ano 14, número $24-2016$

Palavras chaves: Terceirização. Relações de trabalhos. Projeto Lei 4330/2004

\begin{abstract}
The discussion about outsourcing in Brazil emerged from the restructuring of business and economic opening in the late 1980. This article discusses the outsourcing phenomenon in Brazil and their impact on labor relations, from approval recent Bill 4330/2004. We attempted to discuss the factors that characterize the working relationships in outsourcing services, as well as issues related to the consequences of outsourcing processes for employees. They based the work bibliographic research and documentary centered on Brazilian law and manifestations of major unions in the country, the Workers' Central (CUT) and Força Sindical, which as Galvão (2013), took different positions on neoliberal policy and still in manifestation of CLS-Conlutas. The epistemological perspective adopted is the Historical Materialism. It is hoped that this work can instigate further discussions, reflections and looks on this theme.
\end{abstract}

Keywords: Outsourcing. Job Relations. Law Project 4330/2004.

\section{Introdução}

Este artigo visa discutir o fenômeno da terceirização no Brasil e seus impactos sobre as relações de trabalho antes e após a aprovação recente do Projeto de Lei 4330/2004. Para tanto apresenta, como proposta, instigar reflexões acerca da terceirização, apontando as possíveis mudanças provenientes da aprovação deste projeto. Nesse sentido, buscou-se discutir os fatores que caracterizam as relações de trabalho nos serviços terceirizados, assim como as questões relacionadas com as consequências dos processos de terceirização para os trabalhadores.

Neste trabalho, foram realizadas pesquisas bibliográfica e documental, numa perspectiva histórico-crítica, em que, o foco de estudo centrou-se na legislação brasileira e no levantamento de manifestações das principais centrais

TrabalhoNecessário - www.uff.br/trabalhonecessario; Ano 14, № 24/2016. 


\section{Trabalhonecessário}

Issn: $1808-799 X$

ano 14, número $24-2016$

sindicais do país, publicados na internet e em documentos oficiais, a fim de investigar seus posicionamentos, mediante o fenômeno da terceirização e da aprovação do referido projeto, bem como levantar os impactos de sua aprovação.

A obra "Riqueza e Miséria do Trabalho no Brasil II" organizada por Antunes (2013), apresenta as contribuições de Galvão (2013), sobre a trajetória da CUT e da Força Sindical. Em sua obra, a autora trata da flexibilização dos direitos trabalhistas nos governos Fernando Henrique Cardoso e Luiz Inácio Lula da Silva, assim como o movimento de convergência, que progressivamente reduziu as diferenças de posicionamento quanto à flexibilização.

Galvão (2013) enfatiza que o conjunto de medidas da política neoliberal, no Brasil, inclui privatização, desregulamentação e reformas orientadas para o mercado dentre outras. Estas medidas ainda apontam para um Estado Mínimo.

Reflexões sobre estas considerações permitem inferir que apesar destas medidas apontarem para um papel de Estado Mínimo, o Estado não desaparece, continua como regulador e promotor de medidas e legislação de acordo com o interesse da produção, conforme apregoa Marx (2013), ao mencionar que o setor produtivo determina as demais relações.

As considerações de Galvão (2013. P. 366) indicam que, no governo de Fernando Henrique Cardoso, a ação sindical identificou este governo como adversário aos interesses dos trabalhadores, fato que possibilitou uma prática sindical combativa. Já no Governo de Luiz Inácio Lula da Silva, houve certa acomodação e "apesar da criação de novas organizações, a maioria do movimento sindical brasileiro passou a integrar a base de sustentação do governo".

A seguir passaremos a apontar dados e considerações mais especificamente sobre os impactos da flexibilização sobre os trabalhadores. $O$ fato é que, no Brasil, conforme dossiê da Central Única dos Trabalhadores - CUT, elaborado em 2014, acerca do impacto da terceirização sobre os trabalhadores e 


\section{Trabalhonecessário}

Issn: $1808-799 X$

ano 14, número $24-2016$

propostas para garantir a igualdade de direito, constata-se conforme dados da RAIS (2013), que os trabalhadores terceirizados perfazem 26,8 \% do mercado formal de trabalho, totalizando 12,7 milhões de assalariados. Ainda, segundo a CUT, este número é subestimado, pois muitos terceiros estão alocados na informalidade, não sendo contemplados pelas estatísticas, assim como o número de trabalhadores do setor agropecuário.

Diante da dimensão deste fenômeno, espera-se que este trabalho possa instigar novos debates, reflexões e olhares acerca desta temática. A seguir, estão apresentadas considerações sobre o histórico da terceirização no Brasil; sobre o Projeto de Lei 4330/2004 aprovado em 08 de abril de 2015; sobre os aspectos das relações de trabalho nos serviços terceirizados; sobre o posicionamento das Centrais Sindicais acerca da regulamentação deste projeto-lei e sobre os seus impactos nas relações de trabalho.

\section{Terceirização no Brasil}

Em âmbito mundial, Gomes e Luz (2012) apontam que o fenômeno terceirização surgiu com a 2a Guerra Mundial, e se acentuou com o modelo de produção toyotista que passou a externalizar a produção, fato que ainda não ocorria nos modelos de produção "fordismo/ taylorismo", uma vez que estes modelos eram caracterizados pela produção em massa, verticalizada com o trabalhador responsável por apenas uma etapa da produção.

No Brasil, o fenômeno terceirização foi implantado gradativamente, em especial na década de 80 do século XX, com a indústria automobilística. Alguns autores apontam aspectos conceituais da terceirização, que são fundamentais para o entendimento e discussões sobre este assunto. Campos conceitua terceirização como: 


\title{
Trabalhonecessário
}

Issn: $1808-799 X$

ano 14, número $24-2016$

A transferência para uma empresa de prestação de serviços especializados (prestadora) dos serviços não ligados ao objetivo econômico (atividade-fim) da empresa contratante (tomadora), sendo que os serviços serão realizados através dos empregados da prestadora, dentro ou fora da empresa tomadora. (CAMPOS, 2004, p. 296).

Para o autor, a terceirização é reflexo da flexibilização do Direito do Trabalho. Delgado (2012) afirma que o terceirizado é o obreiro, prestador de serviços que realiza as atividades materiais e intelectuais junto à empresa contratante. Para o autor, este fenômeno é novo, ele explica que sua amplitude de dimensão assumiu clareza somente nas últimas três décadas do século $\mathrm{XX}$, no Brasil.

Os textos legais que regulam e tratam sobre a terceirização foram sendo decretados a partir da década de 60 do século XX. Em 1967, o Decreto Lei 200/67, que "dispõe sobre a organização da Administração Federal, estabelece diretrizes para a Reforma Administrativa e dá outras providências", o Artigo 10 trata da descentralização da execução das atividades da Administração Federal, e aponta que:

\begin{abstract}
Para melhor desincumbir-se das tarefas de planejamento, coordenação, supervisão e controle e com o objetivo de impedir o crescimento desmesurado da máquina administrativa, a Administração procurará desobrigar-se da realização material de tarefas executivas, recorrendo, sempre que possível, à execução indireta, mediante contrato, desde que exista, na área, iniciativa privada suficientemente desenvolvida e capacitada a desempenhar os encargos de execução. (BRASIL, DECRETO LEI 200/1967, ARTIGO 10, §7ํㅜ).
\end{abstract}

Em 1970, a Lei 5.645/70 que "estabelece diretrizes para a classificação de cargos do Serviço Civil da União e das autarquias federais, dá outras providências." No Parágrafo único, dispunha-se sobre as atividades relacionadas com transporte, conservação, custódia, operação de elevadores, limpeza e outras assemelhadas, que seriam de preferência executadas mediante contrato. Este parágrafo, porém foi revogado pela Lei 9.527, de 1997. 


\section{Trabalhonecessário}

Issn: $1808-799 X$

ano 14, número $24-2016$

No campo da economia privada, em 1974, foi sancionada a Lei 6019/1974, a qual "dispõe sobre o Trabalho Temporário nas Empresas Urbanas e dá outras Providências". E em 1983, foi sancionada a Lei 7.102/1983 que "dispõe sobre segurança para estabelecimentos financeiros, estabelece normas para constituição e funcionamento das empresas particulares que exploram serviços de vigilância e de transporte de valores e dá outras providências.".

Depois em 1986, criou-se a Súmula 256 que apontava que: "Salvo os casos de trabalho temporário e de serviço de vigilância, previstos nas Leis no 6.019, de 03.01.1974, e 7.102, de 20.06.1983, é ilegal a contratação de trabalhadores por empresa interposta, formando-se o vínculo empregatício diretamente com o tomador dos serviços". Esta súmula, entretanto, não mencionava as formas permitidas e proibidas de terceirização. Em 1993, a Súmula 256/86, foi revista pela Súmula 331 que veio tratar sobre a legalidade de contratos de prestação de serviços. Em 2011, o item IV recebeu nova redação e foram inseridos os itens V e VI com a Resolução 174/2011, cujo objetivo visava esclarecer as responsabilidades dos tomadores de serviços conforme os itens mencionados:

I - A contratação de trabalhadores por empresa interposta é ilegal, formando-se o vínculo diretamente com o tomador dos serviços, salvo no caso de trabalho temporário (Lei no 6.019, de 03.01.1974).

II - A contratação irregular de trabalhador, mediante empresa interposta, não gera vínculo de emprego com os órgãos da Administração Pública direta, indireta ou fundacional (art. 37, II, da CF/1988).

III - Não forma vínculo de emprego com o tomador a contratação de serviços de vigilância (Lei no 7.102, de 20.06.1983) e de conservação e limpeza, bem como a de serviços especializados ligados à atividade-meio do tomador, desde que inexistente a pessoalidade e a subordinação direta.

IV - O inadimplemento das obrigações trabalhistas, por parte do empregador, implica a responsabilidade subsidiária do tomador 


\section{Trabalhonecessário}

Issn: $1808-799 X$

ano 14, número $24-2016$

dos serviços quanto àquelas obrigações, desde que haja participado da relação processual e conste também do título executivo judicial.

V - Os entes integrantes da Administração Pública direta e indireta respondem subsidiariamente, nas mesmas condições do item IV, caso evidenciada a sua conduta culposa no cumprimento das obrigações da Lei n. - 8.666, de 21.06.1993, especialmente na fiscalização do cumprimento das obrigações contratuais e legais da prestadora de serviço como empregadora. A aludida responsabilidade não decorre de mero inadimplemento das obrigações trabalhistas assumidas pela empresa regularmente contratada.

VI - A responsabilidade subsidiária do tomador de serviços abrange todas as verbas decorrentes da condenação referentes ao período da prestação laboral. (TST, RESOLUÇÃO 174/ 2011).

O Departamento Intersindical de Estatísticas e Estudos Socioeconômicos, e CUT (2014) apontam dados sobre Terceirização em um Dossiê acerca dos impactos da terceirização sobre os trabalhadores e propostas para garantir a igualdade de direito.

Este dossiê apresentado pela CUT Nacional e DIEESE em 2014, aborda a distribuição dos trabalhadores em setores tipicamente terceirizados e tipicamente contratantes em 2013, mostrando que a distribuição dos trabalhadores tipicamente terceirizados representa $26,8 \%$ do total de 47.448 .967 das contratações formais, excetuando os setores da agricultura. (RAIS, 2013).

Quando comparadas as condições de trabalho nos setores tipicamente contratantes e nos setores tipicamente terceirizados, os dados revelam que a remuneração média do setor tipicamente contratante em 2013 era $R \$ 2.361,15$, enquanto que nos setores tipicamente terceirizados era $R \$ 1.776,78$, ou seja, a remuneração dos terceirizados é $24,7 \%$ menor que os contratados diretamente. A jornada semanal dos serviços terceirizados também é 3 horas a mais que os tipicamente contratados (RAIS, 2013). 


\section{Trabalhonecessário}

Issn: $1808-799 X$

ano 14, número $24-2016$

Outro fato importante também destacado é quanto ao tempo de emprego em anos. Os serviços terceirizados apresentam um tempo de emprego $53,5 \%$ a menos que os contratados diretamente, demonstrando alto índice de rotatividade. Estes dados confirmam a falta de isonomia e perda de direitos legais adquiridos ao longo do tempo por parte dos trabalhadores.

O Dossiê apresentado pela CUT (2014, p. 9) aponta ainda que "a principal motivação para $91 \%$ das empresas terceirizarem parte de seus processos é a redução de custos e apenas $2 \%$, a especialização técnica". E ainda, do ponto de vista social "a grande maioria dos direitos dos terceirizados é desrespeitada". Este documento também mostra as faces da terceirização, apresentado aspectos deste fenômeno que, em prática, representa riscos para a organização dos trabalhadores e para a negociação coletiva. São eles:

Calote que as empresas terceirizadas dão em seus trabalhadores, principalmente ao final dos contratos de prestação de serviços com as empresas tomadoras desses serviços;

Danos à saúde e vida dos trabalhadores - diversas doenças, acidentes e mortes causadas pela terceirização;

Ataques aos direitos dos trabalhadores terceirizados. Exemplo rebaixamento dos direitos trabalhistas em relação aos trabalhadores diretos, visíveis através de menores remunerações e menos benefícios;

Discriminação em locais de trabalho, especialmente pela proibição do uso do mesmo refeitório dos trabalhadores diretos, pela distribuição de uniformes diferenciados e pela disponibilização de transporte diferente. (CUT, 2004, p. 21-29).

Pelo apresentado, não há como negar que a terceirização significa precarização e fragmentação. Conforme a Central Única dos Trabalhadores, (CUT 2014, p. 30) esclarece que "uma vez que os trabalhadores antes representados por sindicatos com histórico de organização e conquistas, passam a ter como interlocutores entidades ainda frágeis do ponto de vista da capacidade de organização e reivindicação". 


\section{Trabalhonecessário}

Issn: $1808-799 X$

ano 14, número $24-2016$

\section{Terceirizações e capitalismo}

O instituto da terceirização tem origem no sistema capitalista e atualmente é amplamente utilizado no Brasil tanto por órgãos públicos da Administração Pública quanto por empresas privadas e tem sido visto como uma forma de flexibilização dos processos produtivos apontando para agilidade, economia e adaptabilidade. Esse instituto tem sido considerado também como um fenômeno para a adaptação das empresas e do próprio país às mudanças ocorridas no mercado mundial tornando-se inevitável para a sobrevivência de empresas e lucratividade.

No contexto do Direito do Trabalho, a terceirização ainda passa por necessidade de melhor definição, delimitação conceitual e constitui fenômeno na relação de trabalho uma vez que há diferentes aplicações desse instituto no contexto nacional e internacional. Vale, no entanto, salientar que em linhas gerais esses conceitos apresentam elementos bem comuns, ou seja,

1. Empresa Tomadora que é a que contrata a empresa terceirizada, ou seja, terceiriza a atividade de suporte;

2. A atividade-fim é entendida como a atividade principal da empresa e consta na descrição do objeto social da empresa, portanto não sujeita de terceirização;

3. No processo de terceirização a empresa tomada (a que terceiriza parte de seu processo produtivo) transfere atividades para outras empresas ou profissionais autônomos.

De acordo com a Consolidação das Leis de Trabalho - CLT no artigo 581, $\S 2^{\circ}$ entende-se por atividade preponderante a que caracterizar a unidade de produto, operação ou objetivo final, para cuja obtenção todas as demais 
Issn: $1808-799 X$

ano 14, número $24-2016$

atividades convirjam, exclusivamente, em regime de conexão funcional. Desta feita, no Brasil, até esse momento, só é possível terceirizar as atividades meio.

Outra definição que apologiza o conceito de terceirização pode ser encontrado na obra de Ciro Pereira da Silva, cuja a terceirização deve ser entendida como:

[...] a transferência de atividades para fornecedores especializados, detentores de tecnologia própria e moderna, que tenham esta atividade terceirizada como atividade-fim, liberando a tomadora para concentrar seus esforços gerenciais em seu negócio principal, preservando e evoluindo em qualidade e produtividade, reduzindo custos e gerando competitividade (2004, p. 44, apud CARELLI, 2004).

No contexto do Direito do Trabalho Maurício Godinho Delgado, define a terceirização como:

terceirização é o fenômeno pelo qual se dissocia a relação econômica de trabalho da relação justrabalhista que the seria correspondente. Por tal fenômeno insere-se o trabalhador no processo produtivo do tomador de serviços sem que se estendam a este os laços justrabalhistas, que se preservam fixados com uma entidade interveniente. A terceirização provoca uma relação trilateral em face da contratação de força de trabalho no mercado capitalista: o obreiro, prestador de serviços, que realiza suas atividades materiais e intelectuais junto à empresa tomadora de serviços; a empresa terceirizante, que contrata este obreiro, firmando com ele os vínculos jurídicos trabalhistas pertinentes; a empresa tomadora de serviços, que recebe a prestação de labor, mas não assume a posição clássica de empregadora desse trabalhador envolvido (DELGADO, 2006, p. 428).

Desta feita a terceirização, possui natureza jurídica de contrato comercial entre empresas ou pessoas autônomas, prestadores de serviço. No Brasil, o processo de terceirização tem sido verticalizado e defendido em diversas instâncias sociais principalmente o empresariado. 


\section{Trabalhonecessário}

Issn: $1808-799 X$

ano 14, número $24-2016$

$\mathrm{Na}$ verdade, entendemos que o que ocorre no processo de terceirização é a inversão estrutural do mercado de trabalho brasileiro, onde a maior parte dos trabalhadores estará vinculada com as empresas interpostas e a menor parte, contratada diretamente.

Vale salientar que entre 2003 e 2014, o número de trabalhadores terceirizados cresceu de 4 milhões para 13 milhões segundo IBGE, 2015 deste total 11,3 milhões de trabalhadores ganham até 1,5 salários mínimos.

lanni radicaliza este ponto de vista teórico:

Sim, as organizações multilaterais e as corporações transnacionais são novas, poderosas e ativas estruturas mundiais de poder. Elas se sobrepõem e impõem aos Estados nacionais, compreendendo extensos segmentos das sociedades civis, isto é, das suas forças sociais. [...] Sim, já se formaram e continuam a desenvolverem-se estruturas globais de poder, respondendo aos objetivos e às práticas dos grupos, classes ou blocos de poder organizados em escala realmente global. (IANNI, 1998, p. 20).

Outra característica do trabalho é o distanciamento entre o empregador e empregado à partir das formas de gestão do trabalho reduzindo o trabalhador a uma massa desprovida de individualidades e subjetividades.

Segundo Sérgio Pinto Martins, "o grande intéresse da terceirização é a redução dos custos com a mão de obra e por consequencia a precarização das relações de trabalho", (MARTINS, 2009 p. 15-16). Para esse jurista a terceirização nada mais é que a "flexibilização" do Direito do Trabalho que busca adaptar a legislação trabalhista aos anseios de "modernização" dos processos produtivos:

A flexibilização do Direito do Trabalho vem a ser um conjunto de regras que tem por objetivo instituir mecanismos tendentes a compatibilizar as mudanças de ordem econômica, tecnológica ou social existentes na relação entre o capital e o trabalho. (MARTINS, 2009 p. 36). 


\section{Trabalhonecessário}

Issn: $1808-799 X$

ano 14, número $24-2016$

Marx por outro lado, demonstra que as relações de desigualdade estrutural entre pessoas apareciam como meras relações entre coisas, pois a mercadoria, seu fetiche, se reveste de uma relação que oculta a estruturação de poder, a presença de classes e sua organização/desorganização/desigualdade estrutural que atinge o mais simples do sistema produtivo. "O trabalho gasta seus elementos materiais, seu objeto e seus meios, consome-se, é um processo de consumo" (Marx, 1972, p. 126).

Nesse sentido, o processo de trabalho se confunde e funde-se na exploração/opressão que se tornou legitima pelo contrato estabelecido nos códigos do Direito.

"O Contrato é o resultado final no qual suas vontades ganham uma expressão jurídica comum. A igualdade, pois compradores e vendedores só contratam como possuidores de mercadorias, tornando equivalente por equivalente. A propriedade, pois cada um dispõe e pode apenas dispor do que é seu. (...) A única força que os une e põe em contato é a força do seu egoísmo, do seu proveito pessoal, de seu interesse privado. Precisamente por isso, porque cada um cuida apenas de si e ninguém vela pelos outros, graças a uma harmonia pré-estabelecida das coisas ou sob os auspícios de uma providência omniastuta, a realizar a obra do seu proveito mútuo, de sua conveniência coletiva, de seu interesse social". (Marx, 1972, p. 128-129).

Assim, o trabalhador que busca trabalho no contexto capitalista, torna-se um possuidor tal qual o capitalista, seu capital é a força de trabalho que consiste em uma mercadoria. Nesta configuração está posto uma relação jurídica e política, ou seja, a capacidade de produzir do trabalhador identificado como sua força de trabalho que por sua vez por meio da sua produção é convertida em salário e esse salário denota um valor real do trabalho por ele produzido. $\mathrm{O}$ salário é na verdade o pagamento do trabalho realizado.

O próprio sistema de assalariamento do trabalhador é por sua vez profundamente indigno nesse contexto, considerando-se a violência diária em que o trabalhador sofre para executar o trabalho assalariado, pois é submetido a partir 


\section{Trabalhonecessário}

Issn: $1808-799 X$

ano 14, número $24-2016$

da percepção do aumento da jornada formal e informal do trabalho bem como à extensão das funções e paulatinamente à diminuição da remuneração.

Para Marx,

A função verdadeira, específica do capital enquanto capital é, pois, a produção de mais-valor, e essa não é senão produção de sobretrabalho, apropriação - no curso do processo de produção real - de trabalho não pago, que se oferece aos olhos e se objetiviza como mais-valor (MARX,1972, p. 6).

É nesse contexto da busca da formação de uma força produtiva que executa um determinado trabalho que a educação se apresenta como meio de qualificação do trabalho. Segundo Marx,

A fim de modificar a natureza humana, de modo que alcance habilidade e destreza em determinada espécie de trabalho, e se torne força de trabalho desenvolvida e específica, é mister educação ou treino que custa uma soma maior ou menor de valores em mercadorias. Esta soma varia de acordo com o nível de qualificação da força de trabalho. Os custos de aprendizagem, ínfimos para a força de trabalho comum, entram, portanto, no total dos valores despendidos para sua produção. (Marx, 1972, p. 192).

O próprio espaço da cidadania dá lugar ao espaço da produção, onde o operário-cidadão dá lugar ao cidadão-operário. Nesta linha o processo de terceirização em curso no Brasil nada mais é que um dos reclames clássicos do capital para reduzir o custo da mão de obra e aumentar o Lucro por um lado e por outro, esse instituto, no contexto da sua apresentação como sendo necessário para a competitividade das empresas em geral possui, segundo nosso entendimento, como forma de disseminação da ideologia da classe dominante em que expressa a terceirização como um valor a ser alcançado pelos países "desenvolvidos" posto que esse valor é universal, inquestionável e por sua vez força motriz do desenvolvimento econômico e da empregabilidade. 


\section{Trabalhonecessário}

Issn: $1808-799 X$

ano 14, número $24-2016$

\section{Projeto de Lei 4.330/2004 aprovado em 08 de abril de 2015}

É emblemático que a aprovação do Projeto 4330/2004, pela Câmara dos deputados traz mudanças significativas nas relações de trabalho e divide opiniões sobre a terceirização. Sobre esta divisão de opinião trataremos mais adiante. $\mathrm{Na}$ atualidade, a situação do Projeto de Lei 4330/2004 aguarda a apreciação do Senado Federal.

O Projeto de autoria do deputado Sandro Mabel ${ }^{5}$ (2004) sofreu posteriormente regulamentação em seu texto original. As reflexões sobre o texto e sobre as regulamentações posteriores permitem considerar que o projeto apresentava aspectos controversos à medida que, não elucidava sobre proteção jurídica.

Percebe-se também que provocará a precarização do trabalho incompatível com o Estado Democrático de Direito que a Constituição prega, conforme Delgado (2012) menciona ao tratar sobre a audiência pública realizada pelo Tribunal Superior do Trabalho em outubro de 2011, sobre o fenômeno da terceirização.

Considerações sobre este projeto permitem inferir, que a questão da terceirização ainda é polêmica e ainda carece de ser objeto de estudo e discussão.

Mabel (2004) apresenta justificativas para o projeto por ele apresentado, que dispõe sobre o contrato de prestação de serviços a terceiros e as relações de trabalho dele decorrentes, com um discurso que versa sobre as definições de responsabilidade tanto do tomador quanto do prestador de serviços no que se refere à garantia dos direitos dos trabalhadores. Porém para que este trabalhador possa receber seus direitos não será fácil.

\footnotetext{
${ }^{5}$ Sandro Antônio Scodro - nome civil.
} 


\section{Trabalhonecessário}

Issn: $1808-799 X$

ano 14, número $24-2016$

Os pontos polêmicos evidenciados na proposta estão apresentados no Quadro 1, que mostra o que muda com as novas regras para os serviços terceirizados. Estes pontos merecem atenção e discussão, pois caso o projeto seja aprovado, no Senado, da forma como está, questões como direitos e representatividades dos trabalhadores conseguidos ao longo do tempo, serão ainda mais precarizados e tornarão dilemas cruciais para os terceirizados.

O trabalhador, por não ser detentor dos meios de produção, possui unicamente a sua força de trabalho para vender, conforme os ensinamentos de Marx (2013). Muitas vezes os trabalhadores têm direitos, garantidos na constituição, mas não têm condições de cobrá-los, e se submetem as situações precárias e de impunidades, condições análogas ao trabalho escravo, por falta de representatividade.

Neste sentido, os sindicatos podem em muito contribuir com o trabalhador, na medida em que suas bases possuem poder para confrontar abertamente a política governamental caso esta esteja favorecendo as relações de produção precarizando às relações de trabalho. No quadro seguinte, são apontados os pontos controversos, alvos de mudanças. Um dos pontos mais polêmicos trata da questão da mudança dos tipos de atividades que poderão ser contratadas via terceirização. Atualmente somente as atividades-meio podem ser terceirizadas, com a aprovação do projeto, as atividades-fins também poderão ser terceirizadas.

Quadro 1 - Novas regras para serviços terceirizados

\begin{tabular}{|lc|l|ll|}
\hline PONTOS ALVOS DE & JURISPRUDÊNCIA DO TST & PROJETO & DE LEI \\
MUDANÇAS. & POR MEIO DA SÚMULA 331. & $\begin{array}{l}\text { 4330/2004, } \\
\text { PELA CÂMARA EM 08 DE } \\
\text { ABRIL DE 2015. }\end{array}$ \\
\hline
\end{tabular}

${ }^{6}$ Tribunal Superior do Trabalho

TrabalhoNecessário - www.uff.br/trabalhonecessario; Ano 14, № 24/2016. 
ano 14, número $24-2016$

\begin{tabular}{|c|c|c|}
\hline $\begin{array}{l}\text { Responsabilidade das } \\
\text { empresas envolvidas }\end{array}$ & $\begin{array}{l}\text { Responsabilidade subsidiária, } \\
\text { a contratante poderá ser } \\
\text { acionada na Justiça se a } \\
\text { contratada não pagar o } \\
\text { direitos previdenciários. }\end{array}$ & $\begin{array}{l}\text { A contratante deverá } \\
\text { fiscalizar os pagamentos de } \\
\text { salários, 13o salário, férias } \\
\text { entre outros direitos, caso } \\
\text { contrário será considerado } \\
\text { solidário e poderá ser } \\
\text { acionada na justiça } \\
\text { juntamente } \\
\text { contratada. }\end{array}$ \\
\hline $\begin{array}{l}\text { Atividades que podem } \\
\text { ser terceirizadas }\end{array}$ & $\begin{array}{l}\text { Atividade-meio } \quad \mathrm{da} \\
\text { Contratante. }\end{array}$ & $\begin{array}{l}\text { Atividade-meio e atividade- } \\
\text { fins, ou seja, qualquer } \\
\text { atividade, observando que o } \\
\text { texto não se aplica a } \\
\text { administração pública direta, } \\
\text { autarquias e fundações. }\end{array}$ \\
\hline $\begin{array}{l}\text { Representação } \\
\text { sindical/filiação sindical }\end{array}$ & $\begin{array}{l}\text { Livre filiação sindical, mas a } \\
\text { Justiça do trabalho tem } \\
\text { reconhecido a submissão do } \\
\text { contrato de trabalho a acordos } \\
\text { e convenções coletivas com o } \\
\text { sindicato da atividade } \\
\text { preponderante da contratante, } \\
\text { se a terceirização for } \\
\text { considerada irregular ou ilegal. } \\
7\end{array}$ & $\begin{array}{l}\text { O sindicato dos empregados } \\
\text { da contratante representará } \\
\text { os empregados terceirizados } \\
\text { somente se o contrato de } \\
\text { terceirização for entre } \\
\text { empresas que pertençam a } \\
\text { mesma categoria econômica, } \\
\text { garantindo os respectivos } \\
\text { acordos e convenções } \\
\text { coletivas de trabalho }\end{array}$ \\
\hline Troca de empresa & $\begin{array}{l}\text { Não regulamentado, cada } \\
\text { caso tem julgamento distinto. }\end{array}$ & $\begin{array}{l}\text { Manutenção de direitos e } \\
\text { salários antigos nos casos } \\
\text { em que ocorrer troca de } \\
\text { empresa prestadora de } \\
\text { serviços terceirizados com } \\
\text { admissão de empregados. }\end{array}$ \\
\hline $\begin{array}{l}\text { Acesso a restaurante } \mathrm{e} \\
\text { transporte }\end{array}$ & Sem regulamentação & $\begin{array}{l}\text { O trabalhador terceirizado } \\
\text { terá acesso a restaurantes, } \\
\text { transportes e atendimento } \\
\text { ambulatorial oferecidos pela } \\
\text { contratante aos seus }\end{array}$ \\
\hline
\end{tabular}

${ }^{7}$ PIOVESAN, Eduardo. (2015) 
Issn: $1808-799 X$

ano 14, número $24-2016$

\begin{tabular}{|l|l|l|}
\hline & & próprios empregados. \\
\hline $\begin{array}{l}\text { Recolhimento } \\
\text { antecipado de tributos. }\end{array}$ & Sem regulamentação & $\begin{array}{l}\text { A contratante deverá } \\
\text { recolher antecipadamente } \\
\text { parte dos tributos devidos } \\
\text { pela contratada. }\end{array}$ \\
\hline $\begin{array}{l}\text { Contratações feitas pela } \\
\text { Administração Pública }\end{array}$ & Atividade-meio & $\begin{array}{l}\text { O texto não se aplica à } \\
\text { administração pública direta, } \\
\text { autarquias e fundações. }\end{array}$ \\
\hline
\end{tabular}

Quadro 1 - Comparativo. Fonte: CÂMARA NOTÍCIAIS ${ }^{8}$

\section{Aspectos das Relações de Trabalho nos Serviços Terceirizados}

Hobsbawm (1995) ao apresentar considerações sobre o século XX afirma que o avanço tecnológico e as inovações organizacionais impactaram drasticamente as relações de trabalho, e como principal consequência do fenômeno globalização, este autor aponta o desemprego e a precarização nas relações de trabalho. As contribuições deste autor corroboram com os pressupostos da Teoria Marxista, pois, conforme Marx, o que ocorre nas estruturas produtivas impactam diretamente nas superestruturas, assim como está ocorrendo na atualidade com as relações de trabalho. Marx afirma que:

[...] os modos determinados de produção e as relações de produção que lhes correspondem, em suma, de que a "estrutura econômica da sociedade é a base real sobre a qual se ergue uma superestrutura jurídica e política e à qual correspondem determinadas formas sociais de "consciência", de que "o modo de produção da vida material condiciona o processo da vida social, política e espiritual em geral[...] (MARX, 2013, P. 156-157).

No início da década de 1990, o DIEESE9 ${ }^{9}$ realizou uma pesquisa nos setores de metalurgia, bancário e público sobre o tema Terceirização e seus

8 PIOVESAN, Eduardo, Câmara aprova texto-base do projeto que regulamenta terceirização. CÂMARA NOTÍCIAS. Reportagem publicada na internet em 08 de abril de 2015.

9 Departamento Intersindical de Estatística e Estudos Socioeconômicos - Entidade técnica do movimento sindical brasileiro, que atua nas áreas de pesquisa, assessoria e Educação, em temas relacionados ao mundo do trabalho. 


\section{Trabalhonecessário}

Issn: $1808-799 X$

ano 14, número $24-2016$

efeitos sobre as relações de trabalho. Os resultados de diversos trabalhos divulgados impactaram o meio sindical, pois apontaram diversas consequências negativas para os terceirizados e para os sindicatos, como os impactos sobre a isonomia salarial do trabalhador. Pois uma vez que o terceirizado recebe salários mais baixos, não tem direitos a progressões dos planos de cargos e carreira; não recebem benefícios indiretos como vale alimentação; auxílio transporte; assistência médica odontológica entre outros, além de trabalhar em condições de segurança de trabalho mais vulneráveis que os trabalhadores estáveis ou com contratação direta. Na área sindical, o principal impacto é a fragmentação sindical, fato que dificulta a identidade de classe, a mobilização sindical e o fechamento de acordos coletivos.

No início dos anos 90, o termo terceirização tratava-se a rigor de:

Um novo termo cunhado para caracterizar [...] desativação, parcial ou total, de setores produtivos, com a empresa principal deixando de produzir (bens ou serviços) e passando a comprá-los de outras empresas, denominadas terceiras. O segundo significado referese à contratação de uma ou mais empresas terceiras que alocam trabalhadores para a realização de algum serviço ou parte do processo produtivo no interior da empresa principal ( ou empresamãe, como se convencionara denominar as empresas contratantes.(DIEESE, 2004. P. 17-18).

Percebe-se que a terceirização está associada à estratégia empresarial de focar na atividade principal da empresa, e assim investir em qualidade, competitividade e produtividade, deixando as tarefas secundárias para outras empresas, formando assim um modelo trilateral de relação de trabalho, constituído pela relação entre o trabalhador terceirizado, a empresa prestadora dos serviços e a empresa contratante dos serviços.

Assim, o trabalhador terceirizado mantém uma relação de trabalho como os demais trabalhadores contratados formalmente, conforme apontam Gomes e Luz (2012) citando Delgado (2012). Isto porque, no modelo trilateral, também são 


\section{Trabalhonecessário}

Issn: $1808-799 X$

ano 14, número $24-2016$

preenchidos requisitos necessários na relação de trabalho como: 1 ) Trabalho exercido por pessoa física (pessoa natural) logo a figura do trabalhador há de ser sempre uma pessoa física; 2) Pessoalidade - tem haver com a relação de emprego. A pessoa natural não pode ser substituída no que tange ao emprego, exceto, por exemplo em férias ou em afastamentos médicos. Para haver a pessoalidade, o trabalhador escolhido na relação de trabalho é quem exerce a atividade laboral; 3) Trabalho exercido em caráter permanente, não eventual; 4) Onerosidade - o trabalhador recebe pelo trabalho que executa, pela venda do seu trabalho; 5) Subordinação jurídica, conferindo caráter bilateral ao contrato do trabalho, pelo qual o empregado se encontra em situação decorrente da limitação contratual da autonomia de sua vontade, para o fim de transferir ao emprego o poder de direção sobre a atividade que desempenhará.

Nas relações de trabalho do modelo trilateral, a subordinação existente é de caráter jurídico e estrutural. Assim, juridicamente o trabalhador terceirizado obedece à empresa contratada que controla a jornada de trabalho e o local onde este irá exercer suas atividades laborativas. E estruturalmente é subordinado à empresa contratante, pois incorpora a dinâmica cultural da empresa em que está locado. Já à empresa contratante compete oferecer o mesmo tratamento ao trabalhador terceirizado. Teóricos como, Ramos (2001), Pinto (2001), Campos (2004), Gomes e Luz (2012) e Delgado (2012) tratam sobre terceirização no direito do trabalho, apontando desde conceitos, origens e impactos, inclusive na Administração Pública.

Delgado (2012) considera discriminatório pagar ao trabalhador terceirizado remuneração menor que a recebida pelo trabalhador que exerce a mesma função na empresa. Percebe-se que este autor defende que, na relação de trabalho trilateral, o tratamento dado ao trabalhador comum deve ser o mesmo dado ao trabalhador terceirizado, pois este também preenche os requisitos necessários 


\section{Trabalhonecessário}

Issn: $1808-799 X$

ano 14, número $24-2016$

para a caracterização da relação de trabalho e sendo assim merece de amparo jurídico igual.

A aprovação do Projeto de Lei 4330/2004 trouxe à tona discussões relacionadas com a relação de trabalho, com as consequências da regulamentação dos serviços terceirizados e com os posicionamentos dos líderes sindicais e empresários. O texto veio permitir a terceirização em todos os setores, excluindo apenas a Administração Pública Direta, as Autarquias e Fundações. Anteriormente, a Justiça do Trabalho limitava a subcontratação as áreas meio, como limpeza, segurança e serviços especializados que não mantinham relação com o objeto da empresa.

Aspectos das relações de trabalho nos serviços terceirizados são pontos de questionamentos também de vários políticos que se manifestaram mediante a aprovação deste Projeto Lei. Em entrevista concedida aos repórteres, Siqueira e Bittar, publicada no site da Câmara dos Deputados, em 08 de abril de 2015, políticos revelaram seus posicionamentos sobre a proposta de terceirização. Valmir Assunção do PT da Bahia (2015) foi um deles. "A proposta vai retirar dos trabalhadores as conquistas dos últimos 12 anos com a redução do desemprego e a política de valorização do salário mínimo". Para o deputado Sibá Machado do PT do Acre (2015), "a terceirização não permite que nenhum trabalhador de qualquer setor possa pensar em ascensão futura, em cargos de comando".

Já para o deputado Carlos Aleluia do DEM da Bahia (2015), "sindicatos contrários à proposta estão menos preocupados com trabalhadores, e mais com financiamento das entidades sindicais. A proposta vai acabar com a categorização e com o financiamento pelos terceirizados de sindicatos que não Ihes servem". E para o deputado Silas Brasileiro do PMBD de Minas Gerais (2015), "os terceirizados são mais comprometidos com o trabalho e mais eficientes. Quando fui prefeito, fazer concurso foi o maior erro que cometi. Todos 


\section{Trabalhonecessário}

Issn: $1808-799 X$

ano 14, número $24-2016$

sentiram que estavam estáveis e passaram a só cumprir horário, porque estavam estáveis"..

Outros posicionamentos relevantes acerca dos possíveis impactos sobre as relações de trabalho, mediante a aprovação do Projeto Lei 4330/2015, são das Centrais Sindicais Brasileiras: a CUT - Central Única dos Trabalhadores e a Força Sindical.

\section{Posicionamento das Centrais Sindicais Sobre a Regulamentação dos Serviços Terceirizados}

Se não houvesse a regulamentação dos serviços terceirizados, estes seriam regidos pela Súmula 331 do Tribunal Superior do Trabalho. Sobre essa regulamentação, infere-se que há divergências de opiniões nas Centrais Sindicais. Tanto que a Forçal Sindical publicou em seu Jornal eletrônico:

O projeto vai exigir empresas especializadas em apenas uma atividade, aumentando a eficiência dos serviços prestados. Isto vai tirar do mercado firmas que fornecem, por exemplo, mão de obra de limpeza, segurança, refeitório" (Força Sindical, 2015, p. 10).

Entretanto Patrícia Pelatieri, coordenadora do DIEESE, em entrevista dada aos repórteres Carvalhos e Ramos (2015) ressalta a necessidade de cautela e análise minuciosa das armadilhas que o trecho da regulamentação traz. Ela questiona, por exemplo, a subcontratação:

Ora, se está dizendo que empresas são especializadas, por que precisa acionar outra para fazer o trabalho para o qual foi contratada e no qual deveria ser especializada? Na prática, a possibilidade de fazer várias subcontratações burla outra proibição, a defesa do fim da intermediação da mão de obra pregada pelos favoráveis ao projeto. Com a quarteirização, ela continua existindo. (PELATIERI 2015 ${ }^{10}$ ).

10 Disponível em: http://www.cut.org.br/noticias/projeto-no-senado-permitira-terceirizar-caixa-epetrobras-8335/. Acesso em 26 de junho de 2015.

TrabalhoNecessário - www.uff.br/trabalhonecessario; Ano 14, № 24/2016. 


\section{Trabalhonecessário}

Issn: $1808-799 X$

ano 14, número $24-2016$

A Força Sindical destaca as incorporações das ementas de iniciativa do deputado Paulo Pereira da Silva do Partido Solidariedade de SP e ressalta que, sem as incorporações, o projeto aprovado pela Câmara seria o do então deputado Federal Sandro Mabel, o qual implica numa total precarização da mão de obra. Sobre este ponto, a Força destaca que:

Estamos convencidos de que a regulamentação vai criar empresas especializadas, fortalecer os sindicatos combatidos e gerar empregos, calcula Paulinho, ao acrescentar que os sindicados "de carimbo" tenderão a desaparecer com a legislação [...] os terceirizados que exercem atividades-fim serão representados pelos sindicados da categoria e não pelos sindicatos dos funcionários terceirizados [...] vamos assegura aos terceirizados os mesmos direitos concedidos aos funcionários da empresa contratante. (FORÇA SINDICAL, ABRIL 2015 P. 8-11).

Carvalho e Ramos (2015), em sua reportagem, citam a posição de Patrícia Pelatieri, em depoimento a Imprensa da CUT, publicado eletronicamente, em 25 de maio de 2015, "com o projeto aprovado, abre possibilidade de contratação de terceirizados na atividade-fim de estatais e sociedades de economia mista como Banco do Brasil, Petrobrás e Caixa Econômica Federal," uma vez que as restrições são para a Administração Direta, Fundações e Autarquias. E afirma:

[...] ainda que um artigo do texto garanta a representação para o sindicato da categoria preponderante - sindicato dos metalúrgicos, no caso de empresas automobilísticas, sindicato dos bancários, no caso de financeiras, e assim por diante - isso nunca acontecerá porque as terceirizadas serão sempre enquadradas como prestadoras de serviços. [...] Quando conceitua que é especializada em prestação de serviço, esse artigo fica inócuo, porque na caracterização nunca será da mesma categoria econômica. $E$ isso afeta diretamente os sindicatos mais representativos. (PILATIERI, 2015 ${ }^{11}$ ).

11 Disponível em: http://www.cut.org.br/noticias/projeto-no-senado-permitira-terceirizar-caixa-epetrobras-8335/. Acesso em 26 de junho de 2015. 


\section{Trabalhonecessário}

Issn: $1808-799 X$

ano 14, número $24-2016$

Sobre a questão da representação sindical, os autores citados acima, apresentam também o posicionamento do assessor jurídico da CUT, Eymard Loguércio. Para este, o texto do Projeto Lei 4330/2004 estimula a fragmentação sindical dos trabalhadores, além de acabar com a categoria preponderante para avaliar qual sindicato representara determinado grupo de trabalhadores. Percebese então que a discussão sobre a representação sindical é polêmica e ainda carece de muitas discussões.

De acordo com a Agência do Senado (2015), em sua fala sobre a terceirização no país, Maria das Graças Costa da CUT, Secretária de Relações de Trabalho, Gestão 2012-2015, explica: "De cada 10 trabalhadores que adoecem, 8 são terceirizados; quatro de cada cinco mortes registradas em serviço também ocorrem com trabalhadores nessa situação. Não vou nem falar da carga horária e dos salários menores que é um absurdo."

Estas afirmações contrapõem as constatações da Força Sindical de que "pela Regulamentação, não haverá precarização da mão de obra terceirizada", conforme avalia o secretário da força sindical João Carlos Gonçalves, pois a precarização já era uma característica dos serviços terceirizados, mesmo antes da aprovação do Projeto Lei. Galvão (2013) ao tratar sobre a trajetória da CUT e da Força Sindical, afirma que:

A trajetória da Força Sindical revela sua adesão ao neoliberalismo, muito embora essa adesão seja irrestrita, mas sim seletiva (Trópia, 2002 e 2004). Já a trajetória da CUT é mais complexa e oscila entre a assimilação de elementos do discurso neoliberal e a resistência à política Neoliberal (Galvão, 2002).(Galvão 2013, p. 353).

Reflexões sobre esta consideração permitem inferir que houve divergência de posicionamentos das duas Centrais ao longo de suas trajetórias e consequentemente repercussão entre as bases. A autora citada acima afirma que a base social afetada pelo desemprego, pelo aumento da informalidade e pela 


\section{Trabalhonecessário}

Issn: $1808-799 X$

ano 14, número $24-2016$

precarização do trabalho levou a Força Sindical a rever seu posicionamento e a levou a tomar iniciativas em conjunto com a CUT, em especial quanto a greve e a campanha salarial.

Percebe-se em relação ao posicionamento destas Centrais que:

[...] A força sindical adotou posição francamente favorável à flexibilização das relações de trabalho, defendendo a tese de que essa medida era uma forma eficaz de combate ao desemprego e à informalidade. [...] A CUT, ao contrário da Força Sindical, opôs à reforma administrativa e previdenciária e denunciou a política de privatização, a abertura comercial, o desmantelamento dos serviços públicos e o combate aos direitos. Todavia, sua posição é multifacetada e permeada de conflitos internos: enquanto a corrente majoritária, a chamada Articulação Sindical assimilava elementos do discurso neoliberal, as correntes minoritárias, mais identificadas com o pensamento de esquerda, defendiam a preservação da prática sindical combativa que marcou a história da central desde sua criação em 1983 (GALVÃO, 2013, p. 355357).

Observa-se em relação a estes posicionamentos que eles oscilam entre combate e mediação com as políticas que favorecem o capital em detrimento das relações de trabalho.

Para melhor fundamentação deste trabalho, as contribuições da edição online do "Esquerda Diário", são aqui apresentadas por meio de uma conversa com Diana Assunção, dirigente nacional do MRT e também diretora do Sindicato dos Trabalhadores da USP. Conhecida pela luta ao lado das trabalhadoras e trabalhadores terceirizados, Diana afirma:

Desde a fundação da Conlutas em 2006 viemos levantando a necessidade da Central ter um posicionamento claro em relação a terceirização do trabalho. É preciso enfrentar esta divisão que querem impor em nossa classe, entre efetivos, terceirizados, temporários, jovens cidadãos e tantas outras formas de precarizar o trabalho. Por isso é um momento muito importante, pois, existem muitas posições dentro da central. Eu venho estudando este tema já há alguns anos a partir da participação concreta em processos de luta de trabalhadoras terceirizadas. Já tinha essa opinião e somente se comprovou nestas greves: é preciso 


\section{Trabalhonecessário}

Issn: $1808-799 X$

ano 14, número $24-2016$

defender a efetivação de todos os terceirizados sem necessidade de concurso público ou processo seletivo". (ESQUERDA DIÁRIO , 24/03/2016, sem paginação).

As considerações de Diana nos permitem compreender que há outros movimentos, embora também com alguns problemas semelhantes aos das principais Centrais Sindicais, mas que tecem e tendem a críticas pontuais sobre este projeto.

\section{Aprovação do Projeto 4330/2004 e Possíveis Impactos nas Relações de Trabalho e para a sociedade}

De acordo com o DIEESE (2004), o efeito da globalização, na primeira metade dos anos 90, provocou uma terceirização à brasileira, a qual devido a forte retração da economia no país, ao longo do curto governo Collor (1990 1992), foi acelerada. Segundo esta Instituição, o setor produtivo apresenta o discurso da eficácia empresarial contraponto com a precarização para os trabalhadores, pois a terceirização está associada à redução salarial desde a primeira metade de 1990.

A página do Instituto Humanista Unisinos divulga notícia que referencia a reportagem de Piero Locatelli, repórter da ONG Repórter Brasil, publicada eletronicamente, em 07 de abril de 2015. Esta notícia aponta nove consequências da nova Lei da Terceirização. As fontes dessa reportagem, conforme foi divulgado no site da Unisinos, foram: Relatórios e pareceres da Procuradoria Geral da República, CUT, DIEESE, Tribunal Superior do Trabalho, Entrevistas com o auditor-fiscal Renato Bignami e o procurador do trabalho Rafael Gomes.

Segundo esta divulgação, as consequências eminentes da aprovação do Projeto de Lei 4330/2014 serão: 1) Redução de salários e benefícios; 2) Redução do número de empregos, uma vez que o terceirizado trabalha em média 3 horas a mais por semana e consequentemente jornada maior significa redução de vagas 


\section{Trabalhonecessário}

Issn: $1808-799 X$

ano 14, número $24-2016$

em todos os setores; 3) Risco de aumento de acidentes de trabalho, pois os dados da CUT mostram que os terceirizados são os que mais sofrem acidentes de trabalho. Inclusive na Petrobrás, mais de $80 \%$ dos mortos em serviços entre 1995 e 2013 eram subcontratados; 4) Possibilidades de aumento de preconceito no trabalho, 5) Dificuldades de negociação; 6) Multiplicação de trabalho análogo ao escravo, 7) Falta de punição para empregadores; 8) Facilita a corrupção e ainda, poderá fazer com que o Estado diminua a arrecadação e aumente os gastos com despesas por exemplo com o SUS.

Valdete Severo, diretora Cultural da Associação dos Magistrados da Justiça do Trabalho da 4" ${ }^{\text {a }}$ Região do Tribunal Regional do Trabalho, Rio Grande do Sul, em reportagem publicada no site do Sindicato dos Engenheiros do Rio Grande do Sul, cita consequências do Projeto de Lei 4330/2004:

[...] drástica redução na arrecadação e circulação de riquezas e a consequente redução da arrecadação fiscal. E todos nós, consumidores, trabalhadores e empresários, pagamos por isso. É a terceirização que permite que roupas de grife sejam confeccionadas por pessoas mal remuneradas, muitas vezes reduzidas à condição de escravos, sem qualquer controle de qualidade. É a terceirização que provoca o distanciamento insuperável entre o consumidor e a empresa de telefonia, pois instaladores, cabistas, atendentes e técnicos são terceirizados e, portanto, não se sujeitam ao controle e às exigências impostas à concessionária do serviço público. Com a aprovação desse projeto, qualquer produto ou prestação de serviço poderá ser terceirizado e o que está ruim ficará muito pior. (SEVERO, $2015^{12}$.

Por outro lado e contrapondo a estas afirmativas, os defensores do setor produtivo, assim como o texto da regulamentação do projeto em estudo, defendem que os impactos do Projeto de Lei são positivos para o trabalhador, pois a empresa contratante deve garantir as condições de segurança, saúde, alimentação, estendendo aos terceirizados os benefícios oferecidos aos seus

12 Disponível em: http://www.sengers.org.br/site/noticias/1762/artigo-pl-4-330-absurdo-retrocesso. Acesso em 26 de junho de 2015. 


\section{Trabalhonecessário}

Issn: $1808-799 X$

ano 14, número $24-2016$

empregados, além do fato de que a prestadora de serviços, no caso a contratada, deve comprovar o recolhimento de todas as obrigações trabalhistas.

Pelo exposto até aqui, levando em conta os impactos nas relações de trabalho e para a sociedade, percebe-se que ainda serão muitas as discussões acerca deste projeto até sua aprovação no Senado.

\section{Considerações Finais}

Diante dos dados levantados pelas pesquisas realizadas, constata-se que a terceirização surge no Brasil, no fim da década de 1980, como uma forma de transferência para uma empresa de prestação de serviços dos serviços não ligados às atividades-fim da empresa contratante. Percebe-se que hoje é elevado o número de trabalhadores no mercado terceirizado e que as condições em que muitos destes realizam suas atividades são piores que as condições de trabalho dos contratados diretamente, apesar de preencherem todos os requisitos que caracterizam uma relação de trabalho como: trabalho exercido por pessoa física, pessoalidade, não eventualidade, onerosidade e subordinação.

Considera-se que algumas das principais mudanças provenientes da aprovação deste projeto estão ligadas a 1) responsabilidades das empresas envolvidas; 2) mudanças nas atividades que podem ser terceirizadas, pois com este projeto qualquer atividade poderá ser terceirizada, não se aplicando o texto apenas à administração pública direta, autarquias e fundações e 3) representação sindical.

Entretanto, os textos e documentos analisados mostram que estas mudanças poderão proporcionar diversas perdas para os trabalhadores, até mesmo redução de salários, dificuldades para receber seus direitos trabalhistas e 


\section{Trabalhonecessário}

Issn: $1808-799 X$

ano 14, número $24-2016$

de punição de injustiças, dificuldades de progressão de carreira, além da fragmentação sindical e da falta de representatividade, pois pelo Projeto aprovado pela Câmara, muitos trabalhadores por trabalharem na modalidade de contratação terceirizada não conseguirão progressão de cargos e carreira e ainda passarão a ser representados por sindicatos de diferentes categorias.

Considera-se ainda que, apesar de posicionamento diversos das Centrais Sindicais, a aprovação em última instância do Projeto de Lei 4330/2004, nas condições em que foram apresentadas, mesmo com a implementação das regulamentações expostas pela Força Sindical, irão continuar precarizando as condições de trabalho do terceirizado e trarão benefícios relacionados à redução de custos unicamente para o setor produtivo.

Finalmente entende-se que o debate sobre este tema deve ser ampliado, e que não se deve prender aos posicionamentos apenas das principais Centrais Sindicais, mas deve-se observar o movimento, os novos posicionamentos, para fins de formação de novos olhares sobre esta temática e ainda para que, nesta fase de apreciação do Projeto no Senado, possa haver contribuições de todos os sindicatos, para que suas reivindicações, no tocante a este projeto, sejam críticas e pontuais.

\section{Referências}

ALELUIA, Carlos. Terceirização divide opiniões: modernidade para uns, precarização para outros: Depoimento. 08 abr.2015. Câmara dos Deputados. Entrevista concedida a SIQUEIRA, Carol; BITTAR, Paula. Edição: Pierre Triboli. Disponível em: http://www2.camara.leg.br/camaranoticias/noticias/TRABALHO-E-

PREVIDENCIA/485430-TERCEIRIZACAO-DIVIDE-OPINIOES-MODERNIDADE-PARAUNS,-PRECARIZACAO-PARA-OUTROS.html. Acesso em 25 de junho de 2015. 


\section{Trabalhonecessário}

Issn: $1808-799 X$

ano 14, número 24 - 2016

ASSUNÇÃO, Valmir. Terceirização divide opiniões: modernidade para uns, precarização para outros: Depoimento. 08 abr.2015. Câmara dos Deputados. Entrevista concedida a SIQUEIRA, Carol; BITTAR, Paula. Edição: Pierre Triboli. Disponível em: http://www2.camara.leg.br/camaranoticias/noticias/TRABALHO-E-

PREVIDENCIA/485430-TERCEIRIZACAO-DIVIDE-OPINIOES-MODERNIDADE-PARAUNS,-PRECARIZACAO-PARA-OUTROS.html. Acesso em 25 de junho de 2015.

BRASIL. Decreto Lei 200 de 25 de fevereiro de 1967. Dispõe sobre a organização da Administração Federal, estabelece diretrizes para a Reforma Administrativa e dá outras providências. em: http://www.planalto.gov.br/ccivil_03/decreto-lei/Del0200.htm. Acesso em 24 de junho de 2015.

BRASIL. Lei 5.645 de 10 de dezembro de 1970. Estabelece diretrizes para a classificação de cargos do Serviço Civil da União e das autarquias federais, e dá outras providências. Disponível em: http://www.planalto.gov.br/ccivil_03/leis/L5645.htm. Acesso em 24 de junho de 2015.

BRASIL. Lei 6019, de 03 de janeiro de 1974. Dispõe sobre o Trabalho Temporário nas Empresas Urbanas, e dá outras Providências. Disponível em: http://www.planalto.gov.br/CCIVIL_03/leis/L6019.htm. acesso em 24 de junho de 2015.

BRASILEIRO, Silas. Terceirização divide opiniões: modernidade para uns, precarização para outros: Depoimento. Câmara dos Deputados. Entrevista concedida a

SIQUEIRA, Carol; BITTAR, Paula. Edição: Pierre Triboli. 08 abr. 2015. Disponível em: http://www2.camara.leg.br/camaranoticias/noticias/TRABALHO-E-

PREVIDENCIA/485430-TERCEIRIZACAO-DIVIDE-OPINIOES-MODERNIDADE-PARAUNS,-PRECARIZACAO-PARA-OUTROS.html. Acesso em 25 de junho de 2015.

CAMPOS, José Ribeiro. Aspectos da terceirização e o direito do trabalho. Revista do Curso de Direito. Portal Metodista de Periódicos Científicos e acadêmicos. Vol. 1, no 1, 2004.

CARELLI, Rodrigo de Lacerda. Formas atípicas de trabalho. São Paulo: LTr, 2004.

CARRION, Valentim. Comentários à consolidação das leis do trabalho. 34a edição. Atualizada por Eduardo Carrion. Legislação Complementar e jurisprudência. São Paulo: Saraiva, 2009.

CUT. Terceirização e desenvolvimento: uma conta que não fecha. Dossiê acerca do impacto da terceirização sobre os trabalhadores e propostas para garantir a igualdade de direito. Secretaria Nacional de Relações de Trabalho e Departamento Intersindical de Estatísticas e Estudos Socioeconômicos. São Paulo: Central Única dos Trabalhadores, 2014.

DELGADO, Maurício Godinho. Curso de direito do trabalho. 5. ed. São Paulo: LTr, 2006. 


\section{Trabalhonecessário}

Issn: $1808-799 X$

ano 14, número $24-2016$

DELGADO, Mauricio Godinho. Curso de Direito do Trabalho. São Paulo: LTr, 2012.

DIEESE. Caderno do Participante - Dieese. Seminário Terceirização: efeitos sobre as relações de trabalho. Coleção Seminários de Negociação. São Paulo, 2004.

ESQUERDA DIÁRIO ON LINE. Mundo Operário: Conversa com Diana Assunção. Disponível em: http://www.esquerdadiario.com.br/CSP-Conlutas-realizara-Seminariosobre-terceirizacao. Acesso em março/2016.

FORÇA SINDICAL. Terceirização: aprovada regulamentação com emendas trabalhistas. Jornal. Edição 97. Abril 2015.

GALVÃO, Andréia. Sindicalismo e Neoliberalismo: um exame da trajetória da CUT e da Força Sindical. In: ANTUNES, Ricardo (Org.). Riqueza e Miséria do Trabalho no Brasil II. São Paulo: Boitempo, 2013.

GOMES, Philippe; LUZ, Victor. A terceirização no Direito do Trabalho: Causas e Consequências. Revista Direito UNIFACS. Revista eletrônica, no 149. 2012

HOBSBAWM, Eric. Era dos Extremos: o breve século XX: 1914 - 1991. Tradução Marcos Santarrita: Revisão técnica Maria Célia Paoli. São Paulo: Companhia das Letras, 2. Ed. 53a reimpressão, 1995.

IANNI, O. A era do globalismo. Rio de Janeiro: Civilização Brasileira, 2006.

LOCATELLI, Piero. Reportagem. Repórter Brasil, 07 abr.2015. Notícias. UNISINOS. Nove conseqüências da nova lei de terceirização. 08 ABR. 2015 Disponível em: http://www.ihu.unisinos.br/noticias/541501-nove-consequencias-da-nova-lei-da-

terceirizacao. Acesso em 25 de junho de 2015.

LOGUÉRCIO, Eymard. Projeto no Senado permitirá terceirizar Caixa e Petrobras; Para Dieese, PLC 30 abre portas para terceirização no serviço público. Depoimento. CUT Nacional. Imprensa. Reportagem CARVALHO, Luiz; RAMOS, Vanessa. 25 mai. 2015. Disponível em: http://www.cut.org.br/noticias/projeto-no-senado-permitiraterceirizar-caixa-e-petrobras-8335/. Acesso em 26 de junho de 2015.

MACHADO, Sibá. Terceirização divide opiniões: modernidade para uns, precarização para outros: Depoimento. 08 abr.2015. Câmara dos Deputados. Entrevista concedida a SIQUEIRA, Carol; BITTAR, Paula. Edição: Pierre Triboli. Disponível em: http://www2.camara.leg.br/camaranoticias/noticias/TRABALHO-E-

PREVIDENCIA/485430-TERCEIRIZACAO-DIVIDE-OPINIOES-MODERNIDADE-PARA-

UNS,-PRECARIZACAO-PARA-OUTROS.html. Acesso em 25 de junho de 2015.

MAÍRA, Teixeira. Projeto de Lei a favor da terceirização gera racha entre centrais sindicais. IG - Economia, 2015. Disponível em: http://economia.ig.com.br/2015-0407/projeto-de-lei-a-favor-da-terceirizacao-gera-racha-entre-centrais-sindicais.html.

Acesso em 25 de junho de 2015. 


\section{Trabalhonecessário}

Issn: $1808-799 X$

ano 14, número $24-2016$

MARTINS, Sérgio Pinto. A terceirização e o direito do trabalho. São Paulo: Atlas, 2001.

MARTINS, Sérgio Pinto. Direito do Trabalho. 25aㅡ edição. São Paulo: Atlas S.A, 2009.

MARX, Karl. O Capital, 1972.

MARX, Karl. O Capital: crítica da economia política: Livro I: o processo de produção do capital. Tradução: Rubens Enderle. São Paulo: Boitempo, 2013.

PELATIERI, Patrícia. Projeto no Senado permitirá terceirizar Caixa e Petrobras; Para Dieese, PLC $\mathbf{3 0}$ abre portas para terceirização no serviço público. Depoimento. CUT Nacional. Imprensa. Reportagem CARVALHO, Luiz; RAMOS, Vanessa. 25 mai. 2015. Disponível em: http://www.cut.org.br/noticias/projeto-no-senado-permitira-terceirizarcaixa-e-petrobras-8335/. Acesso em 26 de junho de 2015.

PEREIRA, Ciro da Silva. apud CARELLI, Rodrigo de Lacerda. Formas atípicas de trabalho. São Paulo: LTr, 2004, p. 44.

PIOVESAN, Eduardo .Câmara aprova texto-base do projeto que regulamenta terceirização. CÂMARA DOS DEPUTADOS. Edição: PIERRE TRIBOLI. 2015. Disponível em: http://www2.camara.leg.br/camaranoticias/noticias/TRABALHO-EPREVIDENCIA/485428-CAMARA-APROVA-TEXTO-BASE-DO-PROJETO-QUE-

REGULAMENTA-TERCEIRIZACAO.html. Acesso em 24 de junho de 2015.

RAMOS, Dora Maria de. Terceirização na Administração Pública. São Paulo: LTR, 2001.

SEVERO, Valdete. PL 4330 - Absurdo Retrocesso. Sindicato dos Engenheiros do Rio Grande do Sul. Reportagem. 16 abr. 2015. Disponível em: http://www.sengers.org.br/site/noticias/1762/artigo-pl-4-330-absurdo-retrocesso. Acesso em 25 de junho de 2015. 